\title{
Biological effects of carbon nanotubes generated in forest wildfire ecosystems rich in resinous trees on native plants
}

Javier Lara Romero ${ }^{1}$ ， Jesús Campos-García ${ }^{2}$, Nabanita Dasgupta-Schubert ${ }^{3}$ ， Salomón Borjas-García ${ }^{3}$, Dhirendra Kumar Tiwari ${ }^{3}$, Francisco Paraguay Delgado ${ }^{4}$, Sergio Jiménez-Sandoval ${ }^{5}$, Gabriel Alonso Nuñez ${ }^{6}$, Mariela Gómez-Romero ${ }^{7}$, Roberto Linding Cisneros ${ }^{7}$, Homero Reyes De la Cruz ${ }^{2}$, Javier A. Villegas ${ }^{\text {Corresp. }}{ }^{2}$

1 Facultad de Ingeniería Química, Universidad Michoacana de San Nicolás de Hidalgo, Morelia, Michoacán, México

2 Instituto de Investigaciones Químico Biológicas, Universidad Michoacana de San Nicolás de Hidalgo, Morelia, Michoacán, México

3 Instituto de Física y Matemáticas, Universidad Michoacana de San Nicolás de Hidalgo, Morelia, Michoacán, México

4 Centro de Investigación en Materiales Avanzados S.C., Chihuahua, Chihuahua, México

5 Centro de Investigación y de Estudios Avanzados del IPN, Unidad Querétaro, Querétaro, Querétaro, México

${ }^{6}$ Centro de Nanociencias y Nanotecnología, Universidad Nacional Autónoma de México, Ensenada, Baja California, Mexico

7 Instituto de Investigaciones en Ecosistemas y Sustentabilidad, Universidad Nacional Autónoma de México, Morelia, Michoacán, Mexico

Corresponding Author: Javier A. Villegas

Email address: vmoreno@umich.mx

Carbon nanotubes (CNTs) have a broad range of applications and are generally considered human-engineered nanomaterials. However, carbon nanostructures have been found in ice cores and oil wells, suggesting that nature may provide appropriate conditions for CNT synthesis. During forest wildfires, materials such as turpentine and conifer tissues containing iron under high temperatures may create chemical conditions favorable for CNT generation, similar to those in synthetic methods. Here, we show evidence of naturally occurring multiwalled carbon nanotubes (MWCNTs) produced from Pinus oocarpa and Pinus pseudostrobus, following a forest wildfire. The MWCNTs showed an average of 10 walls, with internal diameters of $\sim 2.5 \mathrm{~nm}$ and outer diameters of $\sim 14.5 \mathrm{~nm}$. To verify whether MWCNT generation during forest wildfires has a biological effect on some characteristic plant species of these ecosystems, germination and development of seedlings were conducted. Results show that the utilization of comparable synthetic MWCNTs increased seed germination rates and the development of Lupinus elegans and Eysenhardtia polystachya, two plants species found in the burned forest ecosystem. The finding provides evidence that supports the generation and possible ecological functions of MWCNTs in nature. 
1 Biological effects of carbon nanotubes generated in forest wildfire ecosystems rich in

2 resinous trees on native plants

3

4 Javier Lara-Romero ${ }^{1}$, Jesús Campos-García ${ }^{2}$, Nabanita Dasgupta-Schubert ${ }^{3}$, Salomón Borjas-

5 García $^{3}$, Dhirendra K. Tiwari ${ }^{3}$, Francisco Paraguay-Delgado ${ }^{4}$, Sergio Jiménez-Sandoval ${ }^{5}$, Gabriel

6 Alonso-Nuñez ${ }^{6}$, Mariela Gómez-Romero ${ }^{2,7}$, Roberto Lindig-Cisneros ${ }^{7}$, Homero Reyes de la

7 Cruz $^{2}$, and Javier A. Villegas ${ }^{2}$

8

9 1Facultad de Ingeniería Química, Universidad Michoacana de San Nicolás de Hidalgo, Morelia,

10 Michoacán, México.

11 2'Instituto de Investigaciones Químico-Biológicas, Universidad Michoacana de San Nicolás de

12 Hidalgo, Morelia, Michoacán, México.

13 3Instituto de Física y Matemáticas, Universidad Michoacana de San Nicolás de Hidalgo, Morelia,

14 Michoacán, México.

$15{ }^{4}$ Centro de Investigación en Materiales Avanzados, Unidad Chihuahua, Chihuahua, México.

$16{ }^{5}$ Centro de Investigación y de Estudios Avanzados del IPN, Unidad Querétaro, Querétaro,

17 México.

$18{ }^{6}$ Centro de Nanociencia y Nanotecnología, Universidad Nacional Autónoma de México,

19 Ensenada, Baja California, México.

$20{ }^{7}$ Instituto de Investigaciones en Ecosistemas y Sustentabilidad, Universidad Nacional Autónoma 21 de México, Morelia, Michoacán, México.

22 
23 *Corresponding author: Javier A. Villegas; Instituto de Investigaciones Químico-Biológicas,

24 Universidad Michoacana de San Nicolás de Hidalgo, Edif. A1', Ciudad Universitaria, C.P. 25 58030, Morelia, Michoacán, México. Tel: (52) 443 326-5788. E-mail: vmoreno@umich.mx

26

27

28

29

30

31

32

33

34

35

36

37

38

39

40

41

42

43

44

45 


\section{Abstract}

47 Carbon nanotubes (CNTs) have a broad range of applications and are generally considered

48 human-engineered nanomaterials. However, carbon nanostructures have been found in ice cores

49 and oil wells, suggesting that nature may provide appropriate conditions for CNT synthesis.

50 During forest wildfires, materials such as turpentine and conifer tissues containing iron under

51 high temperatures may create chemical conditions favorable for CNT generation, similar to those

52 in synthetic methods. Here, we show evidence of naturally occurring multiwalled carbon

53 nanotubes (MWCNTs) produced from Pinus oocarpa and Pinus pseudostrobus, following a

54 forest wildfire. The MWCNTs showed an average of 10 walls, with internal diameters of $\sim 2.5$

$55 \mathrm{~nm}$ and outer diameters of $\sim 14.5 \mathrm{~nm}$. To verify whether MWCNT generation during forest

56 wildfires has a biological effect on some characteristic plant species of these ecosystems,

57 germination and development of seedlings were conducted. Results show that the utilization of

58 comparable synthetic MWCNTs increased seed germination rates and the development

59 of Lupinus elegans and Eysenhardtia polystachya, two plants species found in the burned forest

60 ecosystem. The finding provides evidence that supports the generation and possible ecological

61 functions of MWCNTs in nature.

62

63 Introduction

64 Carbon nanotubes (CNTs) have been the subject of extensive research in recent years because of 65 their extraordinary properties and broad range of biotechnological applications. Although CNTs 66 are commonly considered human-engineered nanomaterials, it has been generally accepted that 67 nature may provide appropriate conditions for their synthesis. CNT occurrences have usually 68 been sought in extreme environments (e.g., at high temperatures and pressures), where evidence 
69 has suggested their formation. For example, encapsulated CNTs have been found in the coal-

70 petroleum mix of oil wells (Velasco-Santos et al. 2003) and in Greenland ice-core samples dated

71 from the Neolithic Stone Age (10,000 years ago) (Esquivel \& Murr 2004); however, the source

72 of these CNTs has not yet been identified. There have also been questions regarding the validity

73 of these reports because of the lack of clear high-resolution transmission electron microscopy

74 (HR-TEM) images, Raman analysis, or diffraction patterns (Mackenzie et al. 2008).

75 Previous studies have speculated that CNTs can form in volcanoes, based on the observation that

76 Mount Etna's lava can catalyze the synthesis of multiwalled CNTs (MWCNTs) (Su et al. 2008;

77 Su \& Chen 2007). However, no direct evidence of the formation of CNTs within volcanoes has

78 been confirmed. Further, plant products such as turpentine, eucalyptus oil, neem oil, palm oil,

79 and olive oil have been used as raw materials for chemical vapor deposition (CVD) in CNT

80 synthesis (Afre et al. 2005; Ghosh et al. 2007; Kumar et al. 2011; Suriani et al. 2009). In

81 addition, plant and fungal tissues containing transition metals have been used as natural catalyst

82 precursors in the production of CNTs by CVD (Zhao et al. 2011).

83 Oleoresin extraction is commonly performed in the forestlands of Michoacán, México, where

84 oleoresin is collected from the trunks of living pines, and turpentine is obtained from steam

85 distillation. Alpha-pinene, which is used as a raw material for solvent production, is one of the

86 most important components of turpentine documented as an effective compound from which

87 high-quality and high-yield MWCNTs can be synthesized by CVD (Lara-Romero et al. 2011).

88 Pine species such as Pinus leiophylla, Pinus oocarpa, Pinus montezumae, Pinus pseudostrobus,

89 and Pinus teocote are considered the most important tree species for oleoresin extraction in the

90 Mexican industry. The ecosystems in Michoacán, México, associated with these species of

91 conifers are prone to wildfires. During the drought season, wildfires can cause temperatures 
92 between 600 and $900{ }^{\circ} \mathrm{C}$; this, coupled with the presence of turpentines (or alpha-pinene) and

93 conifer tissues containing iron, provides conditions similar to those required for CNT formation

94 in a process like CVD.

95 Moreover, MWCNTs have also been described as plant growth promoters, favoring seed

96 germination and an increase in the fresh weight of tomato plants (Khodakovskaya et al. 2012;

97 Yang et al. 2017). Recently, nanotechnology tools have developed CNTs for potential

98 applications in agriculture, including crop protection, pollution control, waste management,

99 pesticide detection, nanosensing, and as nanofertilizers (De La Torre-Roche et al. 2012; Gogos et

100 al. 2012; Hong et al. 2013; Khodakovskaya et al. 2012; Yang et al. 2017). Contrary to the

101 beneficial applications of CNTs, negative effects of nanoparticles on edible plants have also been

102 discussed (Miralles et al. 2012); thus, the known effects of MWCNTs on plants are still limited,

103 as are the responses of the natural and agricultural ecosystems to human-engineered

104 nanomaterials (Yang et al. 2017).

105 This report, as a first attempt to understand the roles of crystalline nanomaterials in plant

106 ecosystems and to scarce evidence of naturally-formed MWCNTs in the biosphere. The main

107 objective of this study was to provide evidence of spontaneously and naturally occurring

108 MWCNTs from Pinus species following a forest wildfire event, and their possible effects on

109 germination and development of species found in the burned forest ecosystem.

110

\section{Materials \& Methods}

\section{Sample collection from a pine forest}

113 During the dry season (June 2012), samples of burned wood were randomly collected from

114 mature trees of two different pine forest sites in Michoacán, west-central México, which had 
115 been recently affected by forest wildfires. The sites were 'Cerro Huashan, Nahuatzen' (19³8'35"

116 N, 101 ${ }^{\circ} 56^{\prime} 46^{\prime \prime} \mathrm{W}$; sampling P. oocarpa 2 weeks after fire extinguishment) and 'Cerro de la Cruz,

117 Uruapan' (19²6'40" N, 102 2'56" W; sampling P. pseudostrobus and P. montezumae 8 weeks

118 after fire extinguishment). At least 20 samples of each pinus species were collected from each

119 forest wildfire site. Sampling was collected under the supervision of the Ministry of Environment

120 and Natural Resources specifications (Nom-059-SEMARNAT-2010) and the conservation

121 program for flora and fauna of the Pico de Tancítaro (APFFPT) from Michoacán, México;

122 established by the Mexican decree law of august 19, 2009; and the Program for the Sustainable

123 Management of Mountain Ecosystems Pico de Tancítaro, Michoacán, México (APFFPT-2009).

124 Wood samples were ground and thoroughly mixed for further analyses.

125

126 CNT analysis

127 Samples of burned wood from various types of pine trees were characterized by Raman

128 spectroscopy, thermogravimetry (TGA), and high-resolution transmission electron microscopy

129 (HR-TEM), at least 20 samples of each pinus species were analyzed. Raman spectroscopy was

130 performed using a micro-Raman spectrometer (Labram System model Dilor) equipped with a 20

$131 \mathrm{~mW}$ He-Ne laser emitting at $514 \mathrm{~nm}$, a holographic notch filter (supertNotch-Plus, Kaiser

132 Optical Systems, Inc.), and a $256 \times 1024$ pixel charge-coupled device (CCD) image recorder. All

133 measurements were carried out at room temperature with no special sample preparation.

134 TGA was carried out using a microbalance (Chan D-200) (Doudrick et al. 2012), where 40-50

$135 \mathrm{mg}$ samples of burned wood from the different pine species collected after a natural fire and

136 MWCNTs synthesized by spray pyrolysis of $\alpha$-pinene/ferrocene were air-heated between 25 to

$137700{ }^{\circ} \mathrm{C}$ at a rate of $5^{\circ} \mathrm{C} / \mathrm{min}$, to obtain TGA combustion curves of the samples. 
138 HR-TEM micrographs were obtained from a Philips CM-200 analytical TEM operating at 200

$139 \mathrm{kV}$. Specimens for HR-TEM analysis were prepared by dispersing the samples in acetone

140 through sonication for $2 \mathrm{~min}$ and air-drying a drop of the suspension on a perforated, carbon-

141 coated $\mathrm{Cu}^{\circ}$ grid.

142

\section{Seed germination and plant pot-growing using synthetic MWCNTs}

144 Seeds of Lupinus elegans and Eysenhardtia polystachya, collected from the pine forest of

145 Michoacán, México, were sterilized with 95\% sulfuric acid for 20 min and by soaking in 1\%

146 sodium hypochlorite $(\mathrm{NaOCl})$ for $3 \mathrm{~min}$, respectively; both were then rinsed with sterile distilled

147 water. The seeds of each species were divided into six separate sets of 100 seeds and incubated

148 in a suspension of 0 (Control), 10, 20, 30, 40, or $50 \mu \mathrm{g} / \mathrm{mL}$ MWCNTs (Sigma-Aldrich, St. Louis,

149 MO, USA; Cat. No. 698849; CVD-produced synthetic multiwalled CNTs, OD =6.0-13.0 nm,

$150 \mathrm{ID}=2.0-6.0 \mathrm{~nm}$ length $=2.5-20 \mu \mathrm{m}$, average wall thickness $7-13$ graphene layers, $>98 \%$

151 purity) for $10 \mathrm{~min}$. The MWCNTs were dispersed in water by a three-step acid treatment. First

152 step consists on ultrasonic mixing the MWCNTs with concentrated $\mathrm{HCl}$ for $4 \mathrm{~h}$, after refluxing

153 MWCNTs in nitric acid for $8 \mathrm{~h}$ at $80^{\circ} \mathrm{C}$, and finally refluxing sample in a 1:1 mixture of sulfuric

154 and nitric acids for $4 \mathrm{~h}$ at $80^{\circ} \mathrm{C}$. Each seed set was then placed on moistened filter papers in five

155 Petri plates (20-30 seeds per plate) and randomly distributed in a germination chamber.

156 Germination was evaluated after 10 days of incubation at $26^{\circ} \mathrm{C}$ with a $12: 12 \mathrm{light} /$ dark cycles.

157 Pot-growing tests examined samples from all six treatments, each with 12 replicates (72 plants in

158 total for each seed type). Previously sterilized seeds (as described above) were directly planted in

1595 -cm-diameter polyethylene containers filled with $375 \mathrm{~mL}$ of the growth medium (Creci-root)

160 provided by a local nursery. These containers were then divided into six separate sets and seeds 
161 were treated directly with $1.0 \mathrm{~mL}$ of a suspension of either 0 (Control), 10, 20, 30, 40, or 50

$162 \mu \mathrm{g} / \mathrm{mL}$ MWCNTs, then covered with $\sim 1.0 \mathrm{~cm}$ of plant growth substrate. The containers were

163 arranged at random in trays and watered on alternate days for 5 weeks. At the end of the 5-week

164 period, the plants were harvested, and biometric variables (leaf area and, fresh and dry weights of

165 shoots and roots) were recorded. Data were statistically analyzed using Graph Pad software with

166 an analysis of variance (one-way ANOVA), and mean were compared using Tukey's post hoc

167 tests at a significance level of $p<0.05$.

168

169 Results

170 Identification and characterization of CNTs in the burned wood of resinous forests, after

171 wildfire

172 Burned wood samples were collected after an intense wildfire in a resinous pine forest in the

173 Michoacán state of Mexico (June 2012). This forest mainly comprised P. oocarpa, $P$.

174 pseudostrobus, and P. montezumae. Samples of the carbonized trees of these species were first

175 analyzed by Raman spectroscopy. The Raman spectra of three different burned wood samples

176 indicate that $P$. oocarpa and P. pseudostrobus samples show characteristic bands for CNTs, i.e.,

177 the $D$ and $G$ bands (Fig. 1A). The $D$ band was observed at approximately $1370 \mathrm{~cm}^{-1}$, and the $G$

178 band, also known as the tangential band, was observed at approximately $1600 \mathrm{~cm}^{-1}$, which arises

179 from the $E_{2 g}$ mode of the graphite plane and confirms the presence of $\mathrm{sp}^{2}$ electronic hybridization

180 in the carbon bond network. Unexpectedly, the $2 D\left(G^{\prime}\right)$ band, which is associated with the source

181 or metal load and temperature during synthesis, was not found in the Raman spectra. Moreover,

182 no CNT signals were detected in the samples of burned tree bark obtained from P. montezumae

183 (Fig. 1A). 
184 Thermogravimetric analysis (TGA) was used to determinate the amount of MWCNTs in the

185 burned wood of P. oocarpa, P. pseudostrobus, and P. montezumae (Fig. 1B). Weight losses up to

$186 \sim 150^{\circ} \mathrm{C}$ correspond to the release of water contained in the samples, whereas weight losses in

187 the range of $200-300{ }^{\circ} \mathrm{C}$ and $300-400{ }^{\circ} \mathrm{C}$ are attributed to the degradation of hemicellulose and

188 cellulose, respectively. Weight losses in the range of $370-550{ }^{\circ} \mathrm{C}$ are attributed to the ligneous

189 components such as biochar (Esquivel \& Murr 2004; Mackenzie et al. 2008; Velasco-Santos et

190 al. 2003). Relevantly, the weight loss detected at $610^{\circ} \mathrm{C}$ in the $P$. oocarpa samples, which

191 coincides with that in a synthetic-origin MWCNTs sample, corresponds to CNT combustion.

192 Thus, according to the TGA analysis, P. montezumae contains approximately $10 \%(\mathrm{w} / \mathrm{w})$

193 moisture, 38\% (w/w) hemicellulose, 46\% (w/w) cellulose, and 4\% (w/w) ligneous species; $P$.

194 pseudostrobus is composed of approximately 5\% (w/w) moisture, $7 \%(\mathrm{w} / \mathrm{w})$ hemicellulose, $22 \%$

195 (w/w) cellulose, and 66\% (w/w) of ligneous components; and P. oocarpa is composed of

196 approximately 14\% (w/w) moisture, 18\% (w/w) hemicellulose and cellulose, and 60\% (w/w)

197 ligneous components. Relevantly, the TGA plot indicates that the burned wood samples of $P$.

198 oocarpa contained $\sim 2.8 \%(\mathrm{w} / \mathrm{w})$ of CNTs and P. pseudostrobus less than $0.1 \%(\mathrm{w} / \mathrm{w})$, and the

199 remaining weight of $\sim 5-10 \%(\mathrm{w} / \mathrm{w})$ is attributed to metals and elements.

200 HR-TEM images and fast Fourier transforms (FFTs) of the P. oocarpa samples clearly indicated

201 the presence of CNTs. HR-TEM images and their corresponding FFTs show diffraction patterns

202 characteristic of graphitic crystalline carbon (Fig. 2A-C). HR-TEM data obtained from $P$.

203 oocarpa samples revealed the presence of highly crystalline MWCNTs, consisting of 10 walls

204 with inner and outer diameters of $\sim 2.52 \mathrm{~nm}$ and $\sim 12-15 \mathrm{~nm}$, respectively (Fig. $2 \mathrm{C}$ ). The FFT

205 image displayed one pair of sharp spots, and a line scan along those spots confirmed the presence

206 of sharp spots corresponding to highly ordered carbon (narrow spots). The estimated plane-to- 
207 plane distance between the walls is $0.335 \mathrm{~nm}$, which is in agreement with the nominal distance

208 between the planes in crystalline CNTs (Fig. 2D-E). The bright spots in the dark-field HR-TEM

209 images indicate the presence of metals on the carbon tubes, and the corresponding energy-

210 dispersive X-ray spectroscopy (EDS) analysis confirmed the presence of iron (Fig. 2F),

211 suggesting that this iron could have acted as a catalyst during CNT formation.

212 For the burned wood samples of P. pseudostrobus, HR-TEM images and the corresponding FFT

213 data show preferential formation of coil-shaped nanoparticles consisting of curved crystalline

214 multiwalled carbon layers (Fig. 3A). The FFT images of these MWCNTs reveal one pair of

215 sharp spots and a line scan along those spots confirmed the presence of highly ordered carbon.

216 The estimated distance between the lattice fringes of the carbon walls is $0.335 \mathrm{~nm}$, which is in

217 agreement with the nominal distance between the planes of graphite (Fig. 3B-C). The

218 corresponding EDS analysis reveals the presence of several elements such as calcium, potassium,

219 and phosphorous, but no evidence of the presence of iron or other transition metals is found (Fig.

220 3D). Unexpectedly, no evidence of CNT structures was found in P. montezumae samples;

221 however, amorphous carbon structures were abundant (Fig. 4A-B). The FFT spectrum displayed

222 diffuse spots, characteristic of amorphous carbon, and EDS analysis confirmed the presence of

223 iron, calcium, and phosphorous (Fig. 4C-E). These findings provided evidence of naturally

224 occurring MWCNTs from Pinus species after forest wildfire events.

226 Synthetic multiwalled CNTs increase seed germination in plants growing in resinous Pinus

\section{7 forests}

228 The MWCNTs found in burned P. oocarpa and P. pseudostrobus wood samples had $\sim 10$ layers,

229 with an inner diameter of $\sim 2.52 \mathrm{~nm}$ and an outer diameter of $\sim 14.59 \mathrm{~nm}$. To investigate if 
230 MWCNTs with structural features similar to those found in the natural samples could have a

231 biological effect over some plants species characteristic of these ecosystems (L. elegans and E.

232 polystachya), we conducted a germination and development of seedlings test. This assay was

233 based on previous studies on the positive or negative effects on plant germination and the

234 development of seedlings grown by MWCNT treatment (Hong et al. 2013; Khodakovskaya et al.

235 2012; Miralles et al. 2012). We supplemented the seed germination and early seedling growth

236 with $10-50 \mu \mathrm{g} / \mathrm{mL}$ of the synthetic MWCNTs with structural features similar to those found in

237 the $P$. oocarpa and $P$. pseudostrobus wood samples of burned forest (average wall thickness $\sim 7-$

23813 layers; inner diameter of $\sim 2-6 \mathrm{~nm}$; outer diameter of $\sim 12-20 \mathrm{~nm}$; length of $2.5-20 \mu \mathrm{m})$.

239 Seed germination results showed that the addition of MWCNTs increased the number of

240 germinated seeds and significantly shortened the germination period (Fig. 5A). Seeds of $L$.

241 elegans and E. polystachya treated with MWCNTs exhibited increased germination rates

242 compared to untreated seeds. For L. elegans, a prolific plant in this forest, seed germination rates

243 were $62.5 \%$ higher after the addition of $30 \mu \mathrm{g} / \mathrm{mL}$ of the synthetic MWCNTs compared to those

244 of untreated plants. Moreover, E. polystachya seeds treated with MWCNTs reached germination

245 rates $40 \%$ higher than those of the untreated seeds (Fig. $5 \mathrm{~A}-\mathrm{C}$ ).

246 We further investigated the effects of MWCNTs on the growth and development of L. elegans

247 and E. polystachya seedlings by growing them in a medium supplemented with different

248 concentrations of the synthetic nanoparticles and measuring the yield of variables such as fresh

249 and dry plant biomass, number of lateral roots, and foliar area (Fig. 6A-B). L. elegans plants

250 germinated and grown in the MWCNT dose range of 10 to $50 \mu \mathrm{g} / \mathrm{L}$ exhibited a significant

251 amount of vegetative biomass at $30 \mu \mathrm{g} / \mathrm{L}$ and a decrease at $50 \mu \mathrm{g} / \mathrm{L}$ of MWCNTs (Fig. 6A).

252 Significant increases in the fresh weight of the shoot and root, dry weight of the shoot, number of 
253 lateral roots, and foliar area $(90.23 \%, 132.59 \%, 84.51 \%, 91.05 \%$, and $93.72 \%$, respectively)

254 were observed in treated plants, compared to the untreated plants (Fig. 6C-H). Results also

255 suggest that the plant growth stimulation correlates with the increment in the shoot and root dry

256 weights; when plants were treated with $30 \mu \mathrm{g} / \mathrm{L}$ of MWCNTs these variables reached a

257 maximum of $45.2 \%$ and $120.46 \%$, respectively, compared to those of the untreated plants (Fig.

258 6E-F). E. polystachya plants grown in media supplemented with increasing doses of MWCNTs

$259(10-50 \mu \mathrm{g} / \mathrm{L})$ showed a large vegetative biomass at $50 \mu \mathrm{g} / \mathrm{L}$ and no negative effects of these

260 nanotubes were recorded at any dosage level tested (Fig. 6B). The maximum increases in the

261 shoot and root fresh and dry weight, number of lateral roots, and foliar area $(87.8 \%, 302.78 \%$,

$262148 \%, 114.54 \%, 313.66 \%$, and $150.39 \%$, respectively) were observed in treated plants,

263 compared to the untreated ones (Fig. 6C-H). These results show that synthetic MWCNTs

264 increase seed germination and plant growth in two plant species growing in the studied resinous

265 Pinus forests ecosystem.

266

267 Discussion

268 Our observations clearly support the hypothesis that MWCNTs can be formed spontaneously in 269 nature and are capable of self-assemble without human interference. Although the process was 270 not directly studied, the formation of MWCNTs during a resinous forest wildfire could be the 271 consequence of a synthetic CVD-like mechanism. Production of MWCNTs by CVD requires the 272 presence of volatile carbon compounds, which may act as precursors, in the gaseous state. $P$.

273 oocarpa is a species rich in turpentine, and its oleoresin is a mixture of highly volatile

274 monoterpenes, including $\alpha$ - and $\beta$-pinenes, which have been identified as highly effective

275 MWCNT precursors capable of providing a high yield (Lara-Romero et al. 2011). According to 
276 previous studies, coil-shaped crystalline nanoparticles cannot be synthesized by processes other

277 than CVD (Fejes \& Hernádi 2010; Mhlanga et al. 2011). Therefore, the above hypothesis is also

278 supported by the detection of coil-shaped crystalline carbon nanoparticles in the HR-TEM

279 images of the burned P. oocarpa and P. pseudostrobus wood. In addition, as mentioned above,

280 the impossibility to find MWCNTs into the P. montezumae samples and the sole presence of

281 amorphous carbon structures in this species, indicates that P. montezumae trees lacks either the

282 concentration of catalystics or the type of metal required for an effective synthesis of these

283 structures by a CVD like method (Lara-Romero et al. 2011; Zhao et al. 2011).

284 The presence of iron in the samples of $P$. oocarpa containing MWCNTs suggests that this metal

285 provided catalytically active sites for the CNT synthesis. Previous studies that used plant tissue

286 precursors to catalyze CNT growth have suggested that iron catalytic sites are uniformly

287 distributed in plant cells (Zhao et al. 2011). Consequently, CNTs formed in plant tissues could be 288 expected to have uniform diameters. This is consistent with our HR-TEM observations (average 289 wall thickness $\sim 7-13$ layers; inner diameter of $\sim 2-6 \mathrm{~nm}$; outer diameter of $\sim 12-20 \mathrm{~nm}$; length of $2902.5-20 \mu \mathrm{m}$ ), which revealed that the MWCNTs had homogeneous number of layers and external 291 diameters. In addition, the TGA results indicated that the burned wood samples of $P$. oocarpa 292 after pyrolysis degradation contain $\sim 2.8 \%$ wt of CNTs. Although it has been generally accepted 293 that nature could provide the conditions for their synthesis, there is scarce evidence of naturally 294 formed MWCNTs in the biosphere. Therefore, we provide evidence of spontaneously and 295 naturally produced MWCNTs from Pinus species, following forest wildfires.

296 In another context, the effects of nanomaterials such as CNTs on plant growth and development 297 has been documented, and it has been suggested that their effects are because of factors such as 298 the type of nanoparticles, concentration, plant species, and experimental conditions, including 
299 the method of nanoparticle uptake (Tiwari et al. 2014); in contrast, studies indicate that some

300 CNTs nanomaterials show toxic effects on several plant models (Miralles et al. 2012). With

301 respect to human engineered MWCNTs, several molecular mechanisms involved in their

302 biological effects have been described. Genomic analyses of Lycopersicon esculentum have

303 indicated that exposure to MWCNTs altered the total gene expression, with up-regulation of

304 stress-related genes (Lahiani et al. 2015; Mohamed et al. 2016), while that in Nicotiana tabacum

305 has been found to cause alterations in total gene expression, with up-regulation of genes related

306 to cell-wall assembly/cell growth, regulation of cell cycle progression, and aquaporin production

307 (Lahiani et al. 2015; Miralles et al. 2012; Mukherjee et al. 2016; Yang et al. 2017). Thus, the

308 authors have suggested that size, composition, and specific surface characteristics of the

309 engineered nanomaterials may play important roles in their phytotoxicity (Hong et al. 2013;

310 Mukherjee et al. 2016).

311 In our work, the effect of MWCNTs was evaluated using two plant species found in the burned

312 forest ecosystem, although the MWCNTs utilized are of synthetic origin; these were acquired

313 with structural characteristics similar to those of CNTs found in burned wood samples from the

314 resinous forest. Interestingly, seed germination and growth promotion were observed in both the

315 L. elegans and E. polystachya plant species tested, with the influence of all the quantified

316 biometrical plant variables; it was unlikely that seed germination and growth promotion occurred

317 exclusively owing to water retention in the plant tissues (Fig. 6). In addition, the results did not

318 indicate that CNTs had toxic effects on seed germination or plant development in the

319 concentration range used, suggesting that at low dosages, MWCNTs function as plant-growth

320 promoters. The plant growth dose-dependence also suggests that the concentrations at which

321 CNTs exert their maximum plant growth-promoting effect depend on the plant species. Although 
322 the mechanisms of the observed biological effects were not investigated, the findings indicate

323 that the seed germination and plant-growth promotion was due to the activation of the cell

324 division and nutrient uptake and also increased water influx as previously suggested, rather than

325 an increase in the cell volume.

326 Forest fires are known to enhance the recruitment of a number of important native species

327 associated with forest ecosystems (Keeley \& Fotheringham 1998; Keeley et al. ; Turner et al.

328 1997), including E. polystachya (Orozco 2008) and L. elegans (Díaz-Rodriguez B 2013). In

329 addition, products resulting from the combustion of wood, such as ash (Keeley \& Fotheringham

330 1998) and charred wood (Roy \& Sonie 1992), have also been shown to trigger germination and

331 plant growth after forest fire events. The influence of MWCNTs formed in burned wood after

332 forest wildfires on plant growth or other post-fire characteristic events in terrestrial ecosystems

333 requires extensive studies.

334 CNT formation has usually been associated with extreme environments; however, we have

335 provided evidence that MWCNTs can be found in biotic environments after atmospheric events.

336 MWCNTs, formed in forest wildfires could be introduced into the soil by burned plant material

337 such as smoke or solid particles. If this is true, then MWCNTs have been interacting with soil

338 organisms and plant species since a long time. This may explain our findings, which strongly

339 suggest that MWCNTs produced in resinous forest wildfires promote seed germination and

340 growth of native plants in forest ecosystems.

\section{Conclusion}

343 This study shows direct evidence of MWCNT generation during forest wildfires as a natural

344 phenomenon, strongly suggesting a possible impact on natural plants of the resinous forest 
345 ecosystems through their effects on seed germination and plant growth promotion.

346

347

348

349

350

351

352

353

354

355

356

357

358

359

360

361

362

363

364

365

366

367

368

369

370

371

372

373

374

375
Afre RA, Soga T, Jimbo T, Kumar M, Ando Y, and Sharon M. 2005. Growth of vertically aligned carbon nanotubes on silicon and quartz substrate by spray pyrolysis of a natural precursor: Turpentine oil. Chemical Physics Letters 414:6-10. https://doi.org/10.1016/j.cplett.2005.08.040

De La Torre-Roche R, Hawthorne J, Deng Y, Xing B, Cai W, Newman LA, Wang C, Ma X, and White JC. 2012. Fullerene-enhanced accumulation of p,p'-DDE in agricultural crop species. Environ Sci Technol 46:9315-9323. 10.1021/es301982w

Díaz-Rodriguez B dVE, Gómez-Romero M, Gómez-Ruíz PA, Lindig-Cisneros R. 2013. Conditions for establishment of a key restoration species, Lupinus elegans Kunth, in a Mexican temperate forest. Botanical Sciences 91:8.

Doudrick K, Herckes P, and Westerhoff P. 2012. Detection of Carbon Nanotubes in Environmental Matrices Using Programmed Thermal Analysis. Environmental Science \& Technology 46:12246-12253. 10.1021/es300804f

Esquivel EV, and Murr LE. 2004. A TEM analysis of nanoparticulates in a Polar ice core. Materials Characterization 52:15-25. https://doi.org/10.1016/j.matchar.2004.02.005

Fejes D, and Hernádi K. 2010. A Review of the Properties and CVD Synthesis of Coiled Carbon Nanotubes. Materials 3:2618.

Ghosh P, Afre RA, Soga T, and Jimbo T. 2007. A simple method of producing single-walled carbon nanotubes from a natural precursor: Eucalyptus oil. Materials Letters 61:37683770. https://doi.org/10.1016/j.matlet.2006.12.030

Gogos A, Knauer K, and Bucheli TD. 2012. Nanomaterials in plant protection and fertilization: current state, foreseen applications, and research priorities. J Agric Food Chem 60:97819792. 10.1021/jf302154y

Hong J, Peralta-Videa JR, and Gardea-Torresdey JL. 2013. Nanomaterials in Agricultural Production: Benefits and Possible Threats? Sustainable Nanotechnology and the Environment: Advances and Achievements: American Chemical Society, 73-90. 
376 Keeley JE, and Fotheringham CJ. 1998. Smoke-Induced Seed Germination in California

377

378

379

380

381

382

383

384

385

386

387

388

389

390

391

392

393

394

395

396

397

398

399

400

401

402

403

404

405 Chaparral. Ecology 79:2320-2336. 10.2307/176825

Keeley JE, Pausas JG, Rundel PW, Bond WJ, and Bradstock RA. Fire as an evolutionary pressure shaping plant traits. Trends in Plant Science 16:406-411.

10.1016/j.tplants.2011.04.002

Khodakovskaya MV, de Silva K, Biris AS, Dervishi E, and Villagarcia H. 2012. Carbon nanotubes induce growth enhancement of tobacco cells. ACS Nano 6:2128-2135. $10.1021 / \mathrm{nn} 204643 \mathrm{~g}$

Kumar R, Tiwari RS, and Srivastava ON. 2011. Scalable synthesis of aligned carbon nanotubes bundles using green natural precursor: neem oil. Nanoscale Research Letters 6:92. 10.1186/1556-276X-6-92

Lahiani MH, Chen J, Irin F, Puretzky AA, Green MJ, and Khodakovskaya MV. 2015. Interaction of carbon nanohorns with plants: Uptake and biological effects. Carbon 81:607-619. https://doi.org/10.1016/j.carbon.2014.09.095

Lara-Romero J, Calva-Yañez JC, López-Tinoco J, Alonso-Nuñez G, Jiménez-Sandoval S, and Paraguay-Delgado F. 2011. Temperature Effect on the Synthesis of Multi-Walled Carbon Nanotubes by Spray Pyrolysis of Botanical Carbon Feedstocks: Turpentine, a -pinene and $\beta$-pinene. Fullerenes, Nanotubes and Carbon Nanostructures 19:483-496. 10.1080/1536383X.2010.494785

Mackenzie KJ, See CH, Dunens OM, and Harris AT. 2008. Do single-walled carbon nanotubes occur naturally? Nat Nanotechnol 3:310. 10.1038/nnano.2008.139

Mhlanga SD, Witcomb MJ, Erasmus RM, and Coville NJ. 2011. A novel Ca3(PO4)2-CaCO3 support mixture for the CVD synthesis of roughened MWCNT-carbon fibres. Journal of Experimental Nanoscience 6:49-63. 10.1080/17458081003793313

Miralles P, Church TL, and Harris AT. 2012. Toxicity, Uptake, and Translocation of Engineered Nanomaterials in Vascular plants. Environ Sci Technol 46:9224-9239. $10.1021 /$ es202995d

Mohamed HL, Enkeleda D, Ilia I, Jihua C, and Mariya K. 2016. Comparative study of plant responses to carbon-based nanomaterials with different morphologies. Nanotechnology 27:265102. 
406 Mukherjee A, Majumdar S, Servin AD, Pagano L, Dhankher OP, and White JC. 2016. Carbon

407

408

409

410

411

412

413

414

415

416

417

418

419

420

421

422

423

424

425

426

427

428

429

430

431

432

433

434

Nanomaterials in Agriculture: A Critical Review. Frontiers in Plant Science 7:172.

$10.3389 /$ fpls.2016.00172

Orozco SJ. 2008. Forest Fire Risk Model for Michoacan, Mexico: ITC. https://books.google.com.mx/books?id=_nqBnQAACAAJ

Roy J, and Sonie L. 1992. Germination and Population Dynamics of Cistus Species in Relation to Fire. Journal of Applied Ecology 29:647-655. 10.2307/2404472

Su DS, Chen X, Liu X, Delgado JJ, Schlögl R, and Gajović A. 2008. Mount-Etna-LavaSupported Nanocarbons for Oxidative Dehydrogenation Reactions. Advanced Materials 20:3597-3600. 10.1002/adma.200800323

Su DS, and Chen XW. 2007. Natural lavas as catalysts for efficient production of carbon nanotubes and nanofibers. Angew Chem Int Ed Engl 46:1823-1824.

\subsection{2/anie. 200604207}

Suriani AB, Azira AA, Nik SF, Md Nor R, and Rusop M. 2009. Synthesis of vertically aligned carbon nanotubes using natural palm oil as carbon precursor. Materials Letters 63:27042706. https://doi.org/10.1016/j.matlet.2009.09.048

Tiwari DK, Dasgupta-Schubert N, Villaseñor Cendejas LM, Villegas J, Carreto Montoya L, and Borjas García SE. 2014. Interfacing carbon nanotubes (CNT) with plants: enhancement of growth, water and ionic nutrient uptake in maize (Zea mays) and implications for nanoagriculture. Applied Nanoscience 4:577-591. 10.1007/s13204-013-0236-7

Turner MG, Romme WH, Gardner RH, and Hargrove WW. 1997. Effects of Fire Size and Pattern on Early Succession in Yellowstone National Park. Ecological Monographs 67:411-433. 10.2307/2963464

Velasco-Santos C, Martinez-Hernández AL, Consultchi A, Rodriguez R, and Castaño VM. 2003. Naturally produced carbon nanotubes. Chemical Physics Letters 373:272-276. https://doi.org/10.1016/S0009-2614(03)00615-8

Yang J, Cao W, and Rui Y. 2017. Interactions between nanoparticles and plants: phytotoxicity and defense mechanisms. Journal of Plant Interactions 12:158-169. $10.1080 / 17429145.2017 .1310944$ 
435 Zhao J, Guo X, Guo Q, Gu L, Guo Y, and Feng F. 2011. Growth of carbon nanotubes on natural 436 organic precursors by chemical vapor deposition. Carbon 49:2155-2158. https://doi.org/10.1016/j.carbon.2011.01.030

438

439

440 


\section{Figure 1}

Analysis of the burned wood samples of Pinus species collected after a forest wildfire event.

(A) Raman scattering spectra (He-Ne laser emitting at $514 \mathrm{~nm}$ ) of the Pinus burned wood samples of: (black) MWCNTs produced by chemical vapor deposition method using alphapinene/ferrocene as raw material, (red) P. oocarpa, (blue) P. pseudostrobus, and (green) $P$. montezumae. The characteristic bands of CNTs, i.e., the D band $\left(1370 \mathrm{~cm}^{-1}\right), \mathrm{G}$ band $(1600$ $\left.\mathrm{cm}^{-1}\right)$, and $\mathrm{G}^{\prime}$ band $\left(2640 \mathrm{~cm}^{-1}\right)$ are shown. (B) Thermogravimetric analysis (TGA) of the burned wood samples from $P$. oocarpa, $P$. pseudostrobus, $P$. montezumae, and synthetic MWCNTs (pyrolyzed at $610^{\circ} \mathrm{C}$ ).
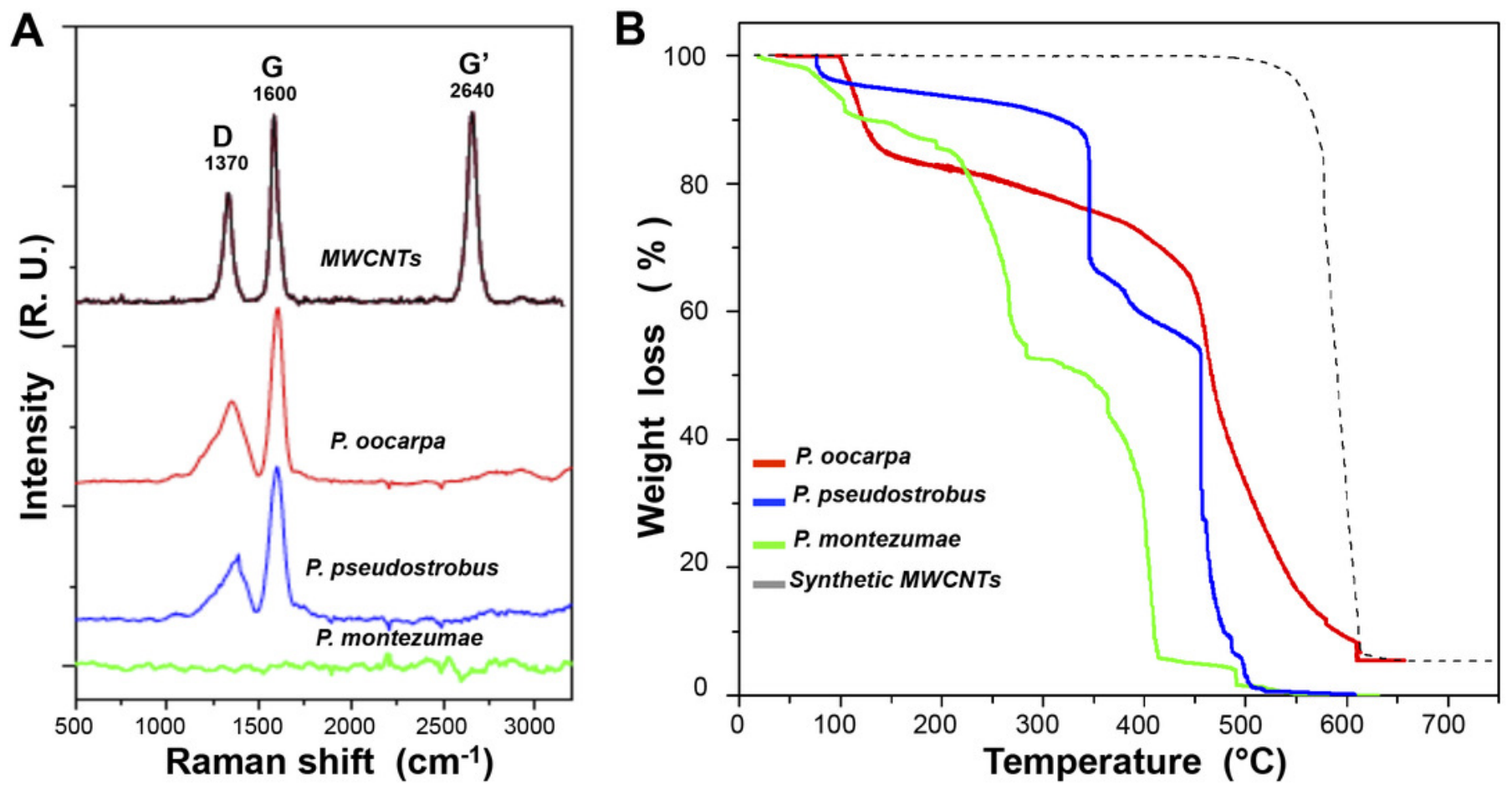


\section{Figure 2}

Identification of MWCNTs in the burned wood samples of Pinus oocarpa collected after a forest wildfire event.

(A-C) HR-TEM images of the burned wood samples at different magnifications, (D) FFT image, (E) analysis of the FFT image, and (F) EDS analysis. Representative images are shown.
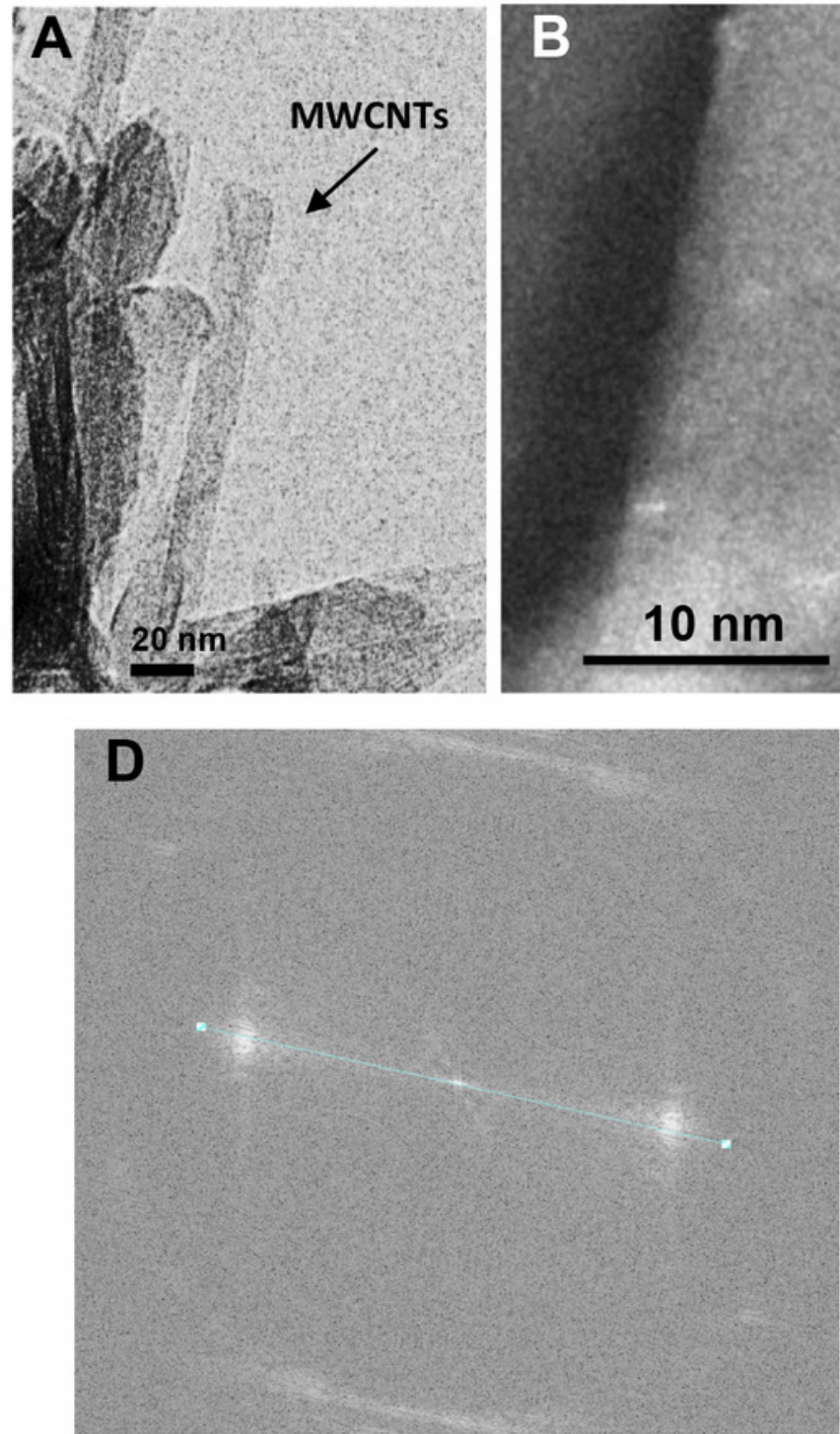
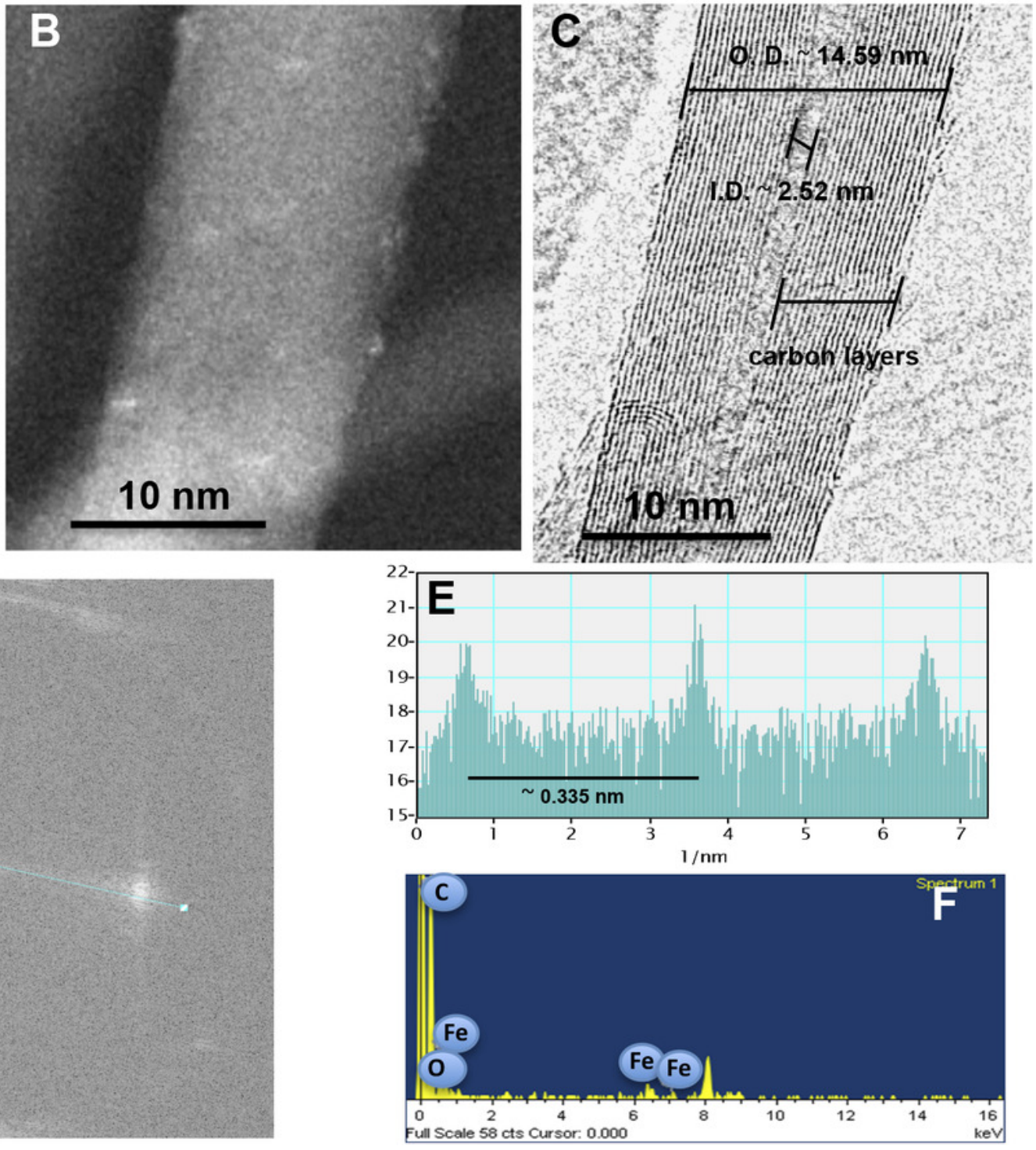


\section{Figure 3}

Identification of MWCNTs in the burned wood samples of Pinus pseudostrobus collected after a forest wildfire event.

(A) HR-TEM images of the burned wood samples at several magnifications, (B) FFT image, (C) FFT analysis, and (D) EDS analysis. Representative images are shown.

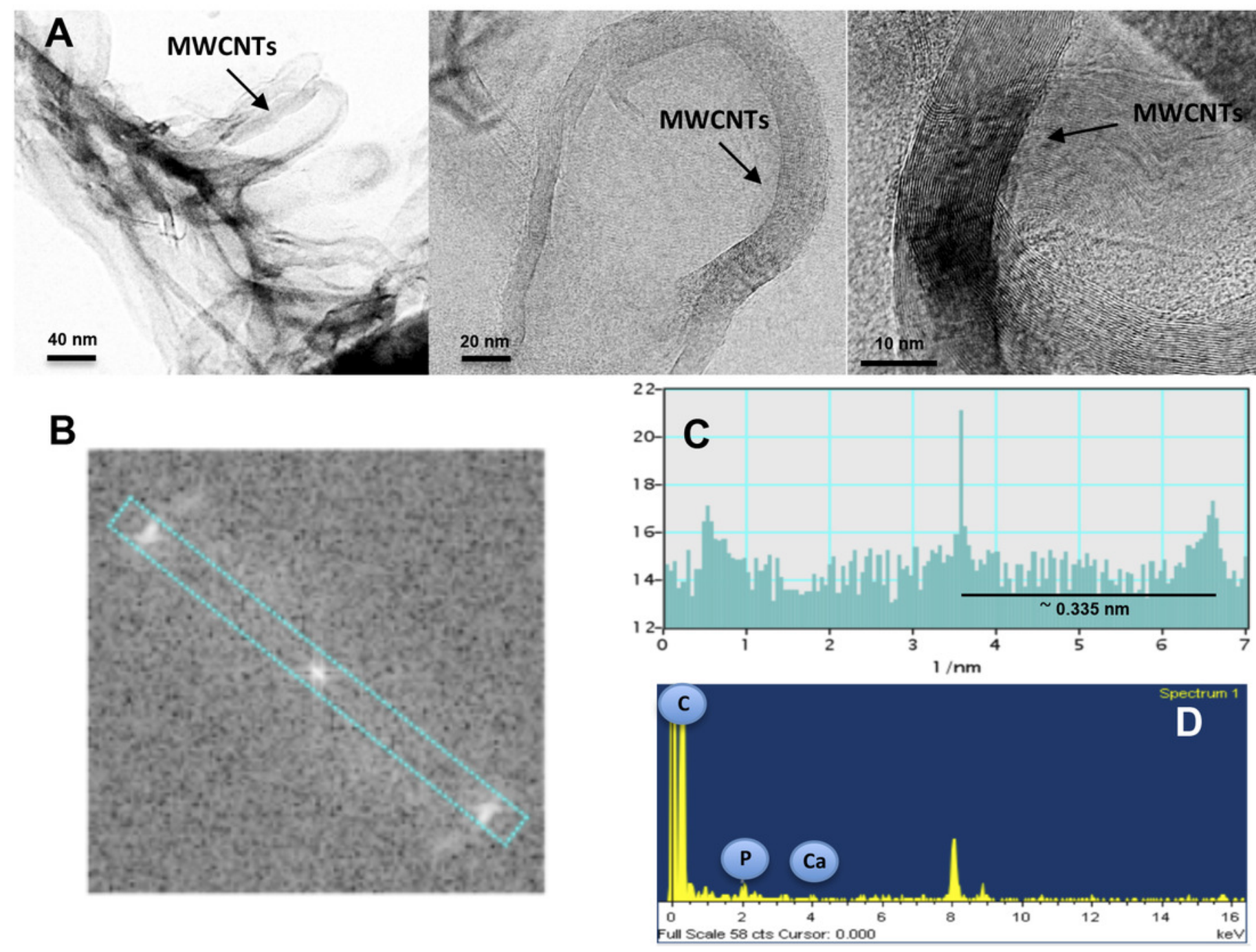




\section{Figure 4}

Identification of the carbon structures in the burned wood samples of Pinus montezumae collected after a forest wildfire event.

(A) HR-TEM images of the burned wood samples at several magnifications, (B) FFT image, (C) FFT analysis, and (D) EDS analysis. Representative images are shown.
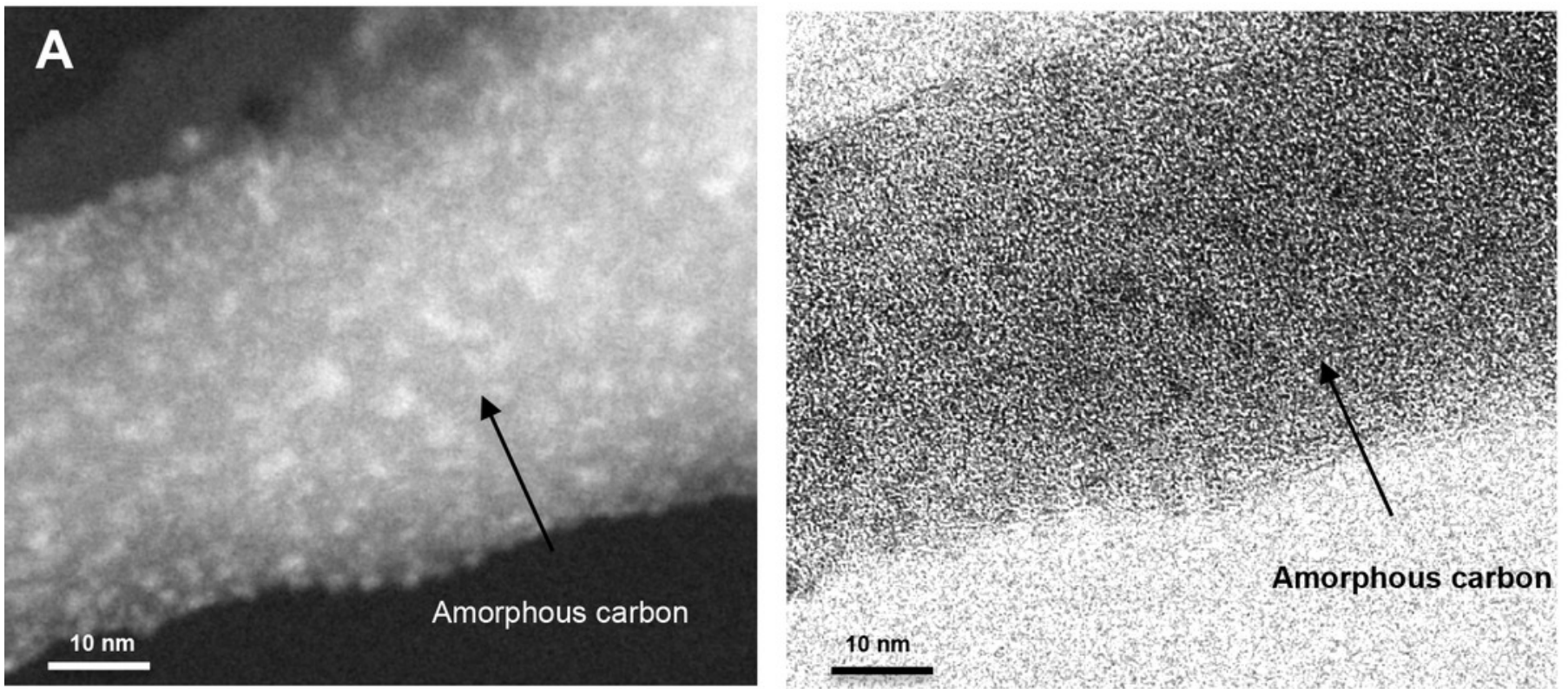

Amorphous carbon

B
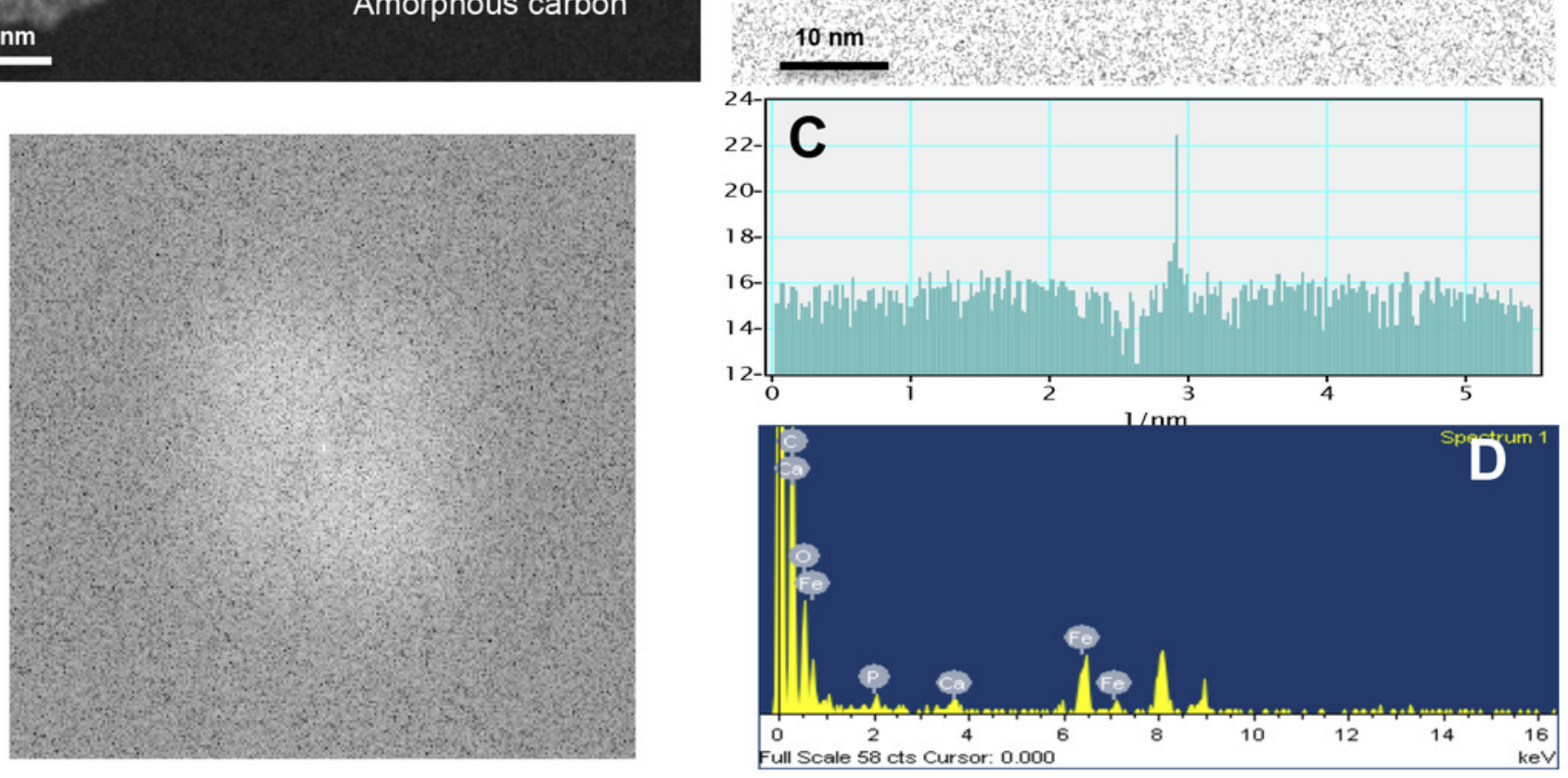


\section{Figure 5}

Effect of synthetic MWCNTs on the seed germination rate of Lupinus elegans and Eysenhardtia polystachya.

Seed germination of the native plants from the Pinus forest was evaluated after 10 days with MWCNTs treatment and recorded after 5-week of cultivation. (A) L. elegans seed
germination,
(B) E. polystachya seed germination,
(C) quantitative data
(A) and
(B) assays.

Bars represent mean \pm standard error of three independent experiments, $n=30$ each. Oneway analysis of variance (ANOVA) was carried out with Tukey's post hoc test; statistical significance $(P<0.05)$ between treatments with respect to control is indicated with different lowercase letters.
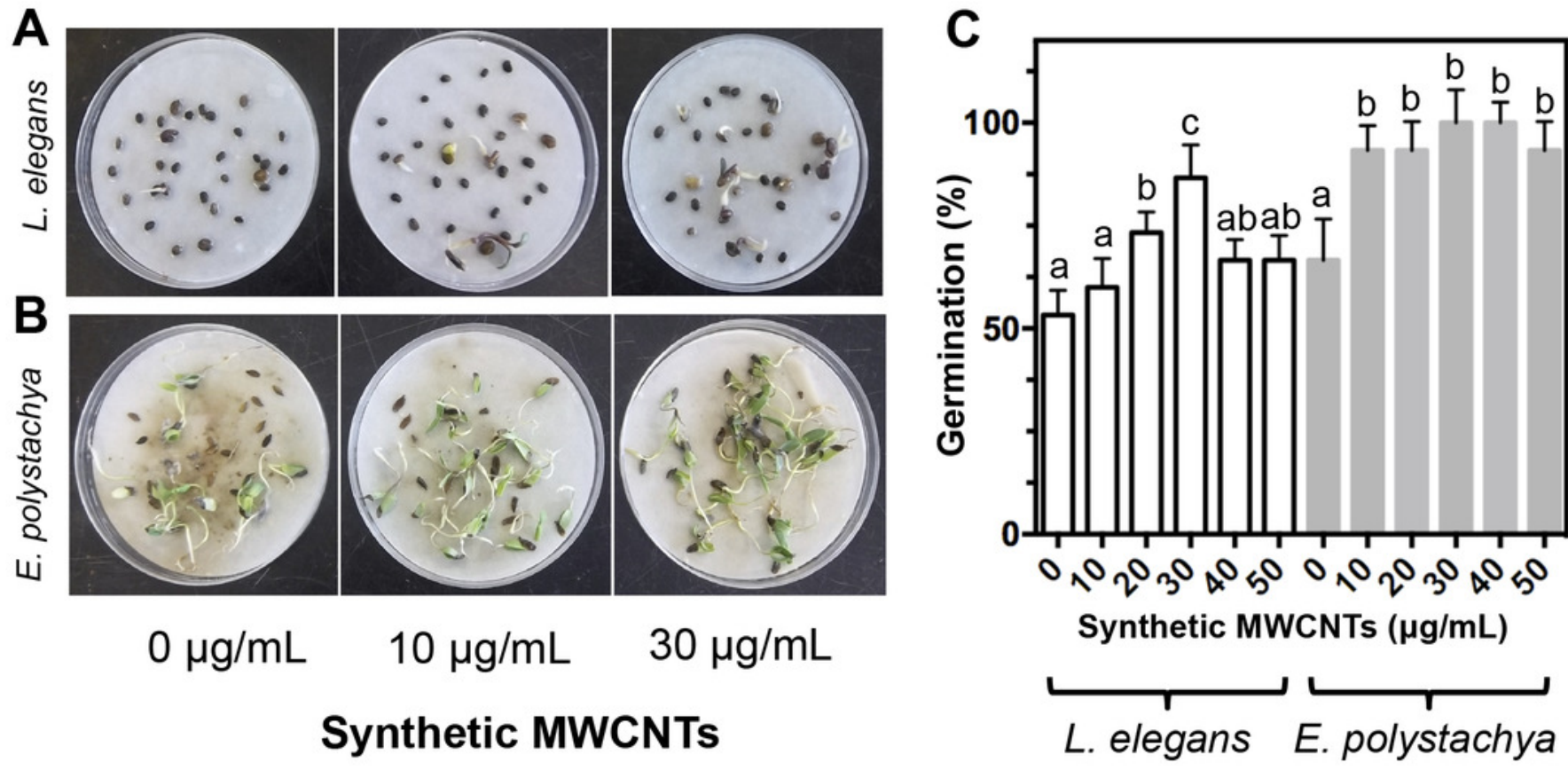


\section{Figure 6}

Effect of synthetic MWCNTs on the plant growth rate of Lupinus elegans and Eysenhardtia polystachya.

After seed germination of the native plants from the Pinus forest (as described above), they were planted in 5-cm-diameter polyethylene containers filled with growth medium (Creciroot). These containers were then divided into six separate sets and the seedlings were treated directly with $1.0 \mathrm{~mL}$ of the suspension consisting of either 0 (control), 10, 20, 30, 40, or $50 \mu \mathrm{g} / \mathrm{mL}$ of synthetic MWCNTs. At the end of the 5 -week period, the plants were harvested, and biometric variables were recorded. (A) L. elegans plant growth, (B) E. polystachya plant growth, (C) determination of the growth variables (A) and (B) assays: (C) shoot in fresh weight, (D) root in fresh weight, (E) shoot in dry weight, (F) root in dry weight, (G), lateral roots number, and $(\mathbf{H})$ foliar area. Bars represent mean \pm standard error of three independent assays, $n=72$. One-way analysis of variance (ANOVA) was carried out with Tukey's post hoc test; statistical significance $(P<0.05)$ between treatments with respect to control is indicated with different lowercase letters. 


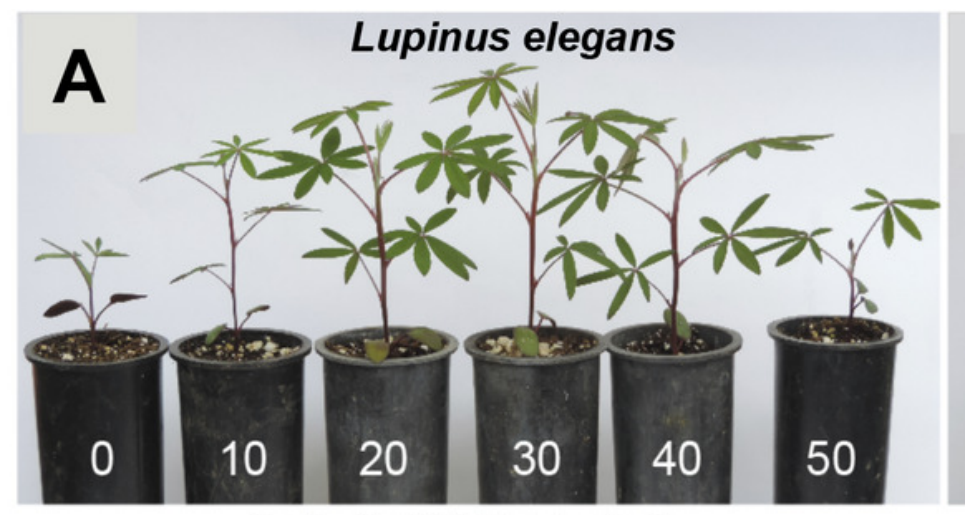

Synthetic MWCNTs $(\mu \mathrm{g} / \mathrm{mL})$
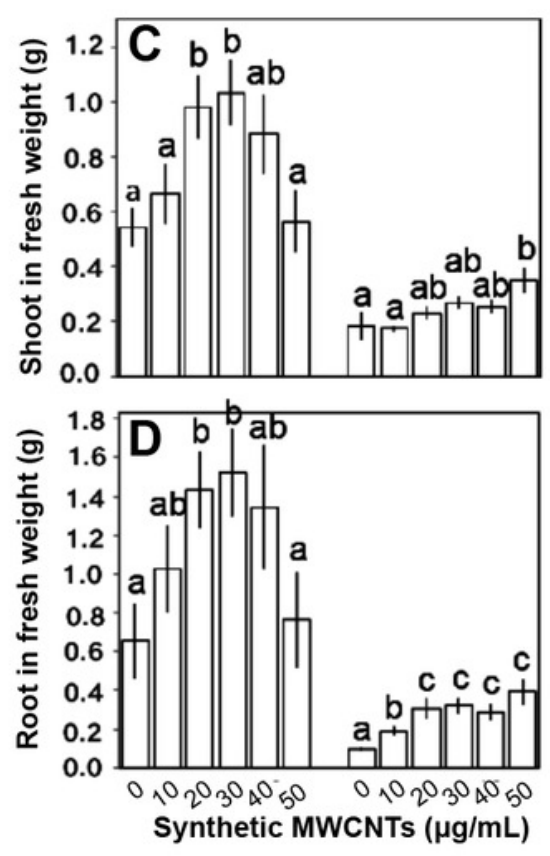

L. elegans

E. polystachya
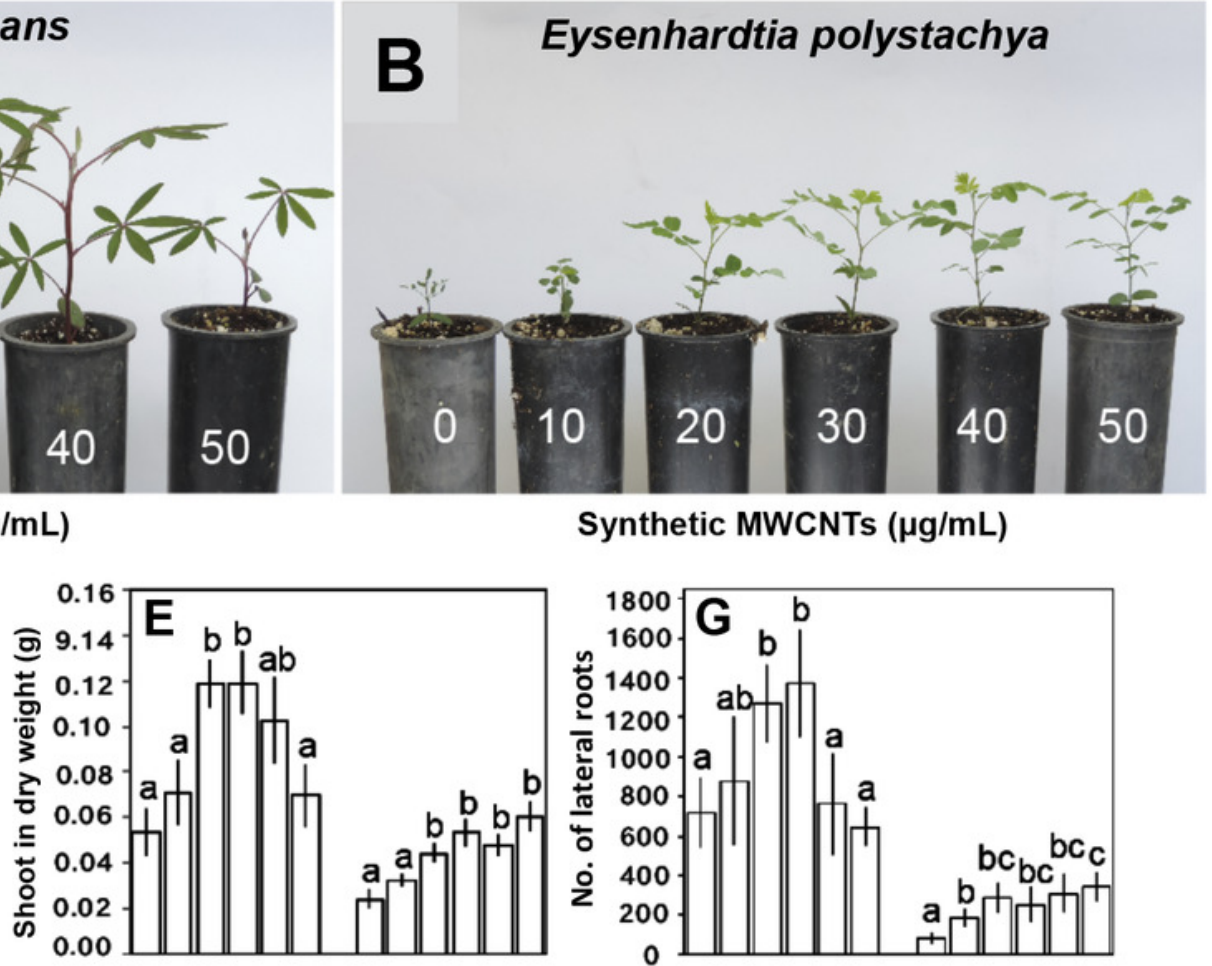

Synthetic MWCNTs $(\mu \mathrm{g} / \mathrm{mL})$
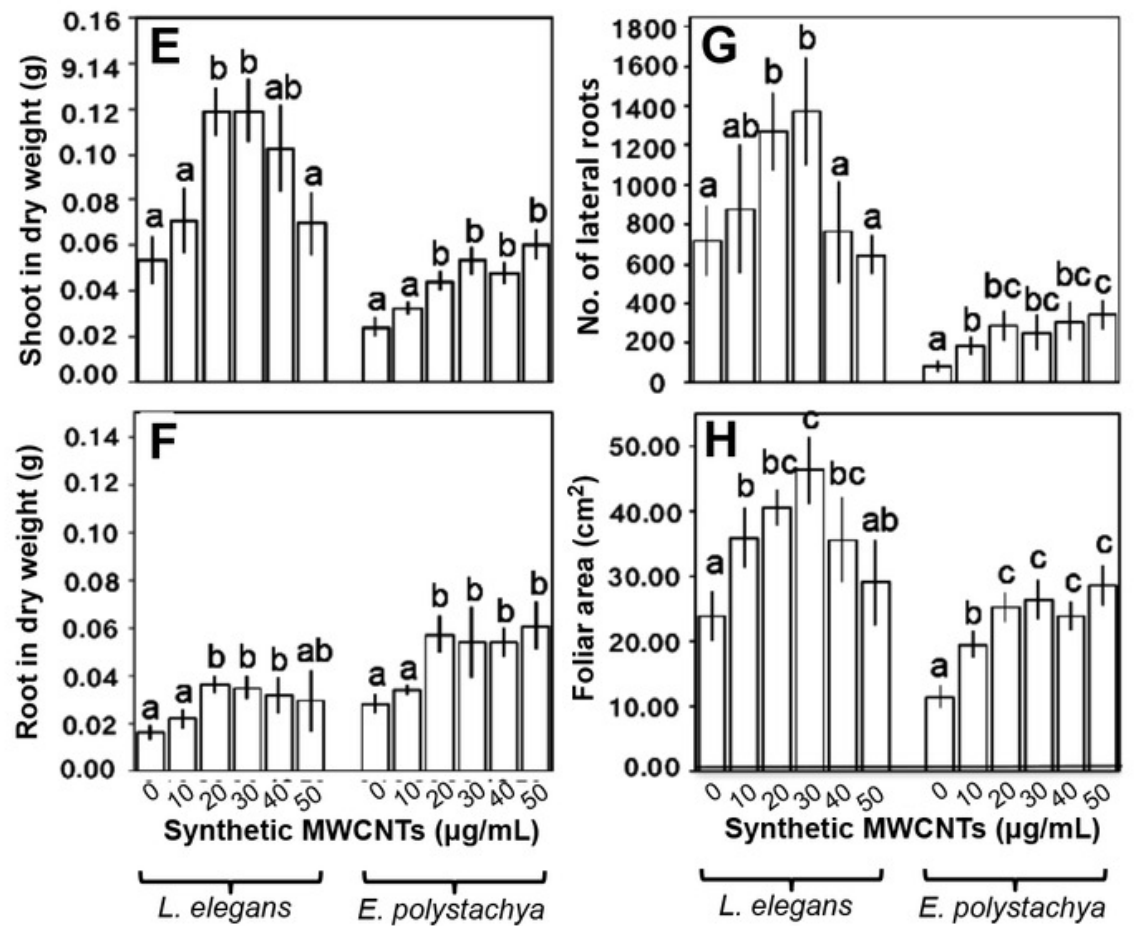

E. polystachya 